\title{
Targeted therapy of human osteosarcoma with 17AAG or rapamycin: Characterization of induced apoptosis and inhibition of mTOR and Akt/MAPK/Wnt pathways
}

\author{
YAIR GAZITT, VENKATASUBBARAO KOLAPARTHI, KARLA MONCADA, \\ CHARLES THOMAS and JAMES FREEMAN \\ Cancer Therapy \& Research Center, The University of Texas Health Science Center at \\ San Antonio, San Antonio, TX, USA
}

Received August 22, 2008; Accepted October 3, 2008

DOI: 10.3892/ijo_00000181

\begin{abstract}
Osteosarcoma is highly resistant to current chemotherapy regimens. Novel therapeutic approaches, potentially involving targeting of specific survival pathways, are needed. We used 17-AAG to inhibit Hsp90 and rapamycin to inhibit mTOR, in the osteosarcoma cell lines, HOS and KHOS/NP. HOS and KHOS cells were treated for 24 and $48 \mathrm{~h}$ with 17-AAG or rapamycin and studied drug-induced apoptosis, cell cycle, mitochondrial membrane potential and levels of reduced glutathione (GSH), dephosphorylation of signal transduction proteins in the Akt/MAP kinase pathway and mTOR signaling. 17-AAG was a potent inducer of apoptosis, involving effective depletion of GSH and mitochondrial membrane (MM) depolarization, strong activation of caspase-8 and -9 and release of AIF from mitochondria to the cytosol. Furthermore, 17-AAG down-regulated pAkt, p44Erk, p-mTOR, p70S6, TSC1/2 and pGSK-3ß. Treatment with 17-AAG also caused down-regulation of cyclin D1, GADD45a, GADD34 and pCdc2 and upregulation of cyclin B1 and mitotic block. A decrease in Hsp90 and increase in Hsp70 and Hsp70 C-terminal fragments were also observed. Rapamycin was a less potent inducer of apoptosis, involving a small decrease in GSH and MM potential with no activation of caspases or release of AIF. Rapamycin strongly inhibited cell growth with an increase in G1 and a decrease in S-phase of the cell cycle concomitant with down-regulation of cyclin D1. Rapamycin also downregulated the activity of p70S6, pAkt and p-mTOR, but had no effect on pGSK-3ß, p44Erk, pCdc2, TSC1/2 or Hsp70 or Hsp90. We conclude that Hsp90 inhibition merits further study in the therapy of osteosarcoma.
\end{abstract}

Correspondence to: Dr Yair Gazitt, Cancer Therapy \& Research Center at The University of Texas Health Science Center, 7703 Floyd Curl Drive, San Antonio, TX 78284, USA

E-mail: gazitt@uthscsa.edu

Key words: 17AAG, rapamycin, sarcoma, apoptosis, Hsp90, Akt/mTOR

\section{Introduction}

Sarcomas encompass a heterogeneous group of malignancies of mesenchymal origin, accounting for approximately $1 \%$ of adult malignancies, while soft tissue sarcomas comprise $7 \%$ and osseous sarcomas comprise $5 \%$ of childhood malignancies $(1,2)$. Adult osteosarcoma is the second most frequent sarcoma with a low rate of response to current therapy due to inherent chemoresistance. Surgery, with or without radiation therapy represents the mainstay of therapy for early stage soft tissue sarcomas, while adjuvant chemotherapy is controversial. Preand post-operative chemotherapy play prominent roles in the treatment of bone sarcomas, such as anthracycline and/or ifosfamide-based chemotherapies which are the principal therapeutic agents in the adjuvant and metastatic soft tissue sarcomas settings. The response rates ranged between 15 and $65 \%(3-5)$. However, the majority of patients relapse and overall survival is dismal (6-8). Hence, there is a need to develop newer, novel therapeutic agents. Potential therapeutic approaches include targeting of angiogenesis, protein kinases, heat-shock protein 90 (Hsp90) and mammalian target of rapamycin (mTOR) signaling (9-13).

mTOR is key serine/threonine kinase acting downstream of the activation of Akt. Current data suggest that mTOR acts as a 'master switch' of cellular metabolism and key element in the growth and proliferation, particularly in the regulation of tumor cell proliferation and metastasis. mTOR is central to the regulation of apoptotic cell death involving p53, BAD, Bcl-2, p27 and c-Myc (14). Akt activates mTOR by activating the mTOR upstream regulator, tuberous sclerosis complex $1 / 2$ (TSC1/2), which in turn activates Rheb to phosphorylate mTOR complex 1 (mTORC-1). mTORC-1 then complexes with Raptor to phosphorylate p70S6 kinase for downstream activation of the S6 ribosomal protein to initiate protein synthesis. The mTORC1/Raptor complex also dissociates 4E-BP from eIF4-E resulting in activation of eIF4-E and overall protein synthesis $(14,15)$. Hence, dysregulated mTOR activity is associated with several hamartoma syndromes, including tuberous sclerosis complex, and many types of cancer (16-20).

Several mTOR inhibitors have been studied in phase I/II clinical trials. Rapamycin (sirolimus), the rapamycin analogues 
CCI-779 (temsirolimus) and AP23573 were recently studied in phase I trials in patients with solid tumors $(21,22)$.

The heat-shock family of proteins, Hsp27, Hsp60, Hsp70, and Hsp90 are chaperone proteins and serve an important role in the regulation of cell stress and cell growth by affecting the turnover of client proteins to increase or decrease their intra-cellular activities through changes in their 3-D conformation and degradation (23). Hence, by interacting with a great variety of proteins, HSPs are capable of regulating oxidative stress, hypoxia, cell cycle, cell growth, cell death, angiogenesis and metastasis $(23,24)$. In the apoptosis pathway, p53, BAD, caspase-3 and -9, Apaf-1, cytochrome $\mathrm{c}$ and AIF are the primary targets $(23,24)$. Hsp90 is unique among chaperone proteins in its role as 'super chaperone' with strong ATPase activity and the capability to mobilize other chaperone proteins. Among the important targets of Hsp90 are the growth regulatory pathways of Akt, Bcr-abl; Raf/Ras pathway; MAP and Erk kinase pathways; VEGF and cyclin-dependent kinases $(25,26)$. Hsp90 also facilitates the translocation of proteins such as p53 and mdm2 into the nucleus. In general, Hsp90 increases p53 stability and translocation to the nucleus and therefore it is considered a positive regulator of wt p53, whereas, stabilization of mutant p53 requires interaction of Hsp90 with the co-chaperone Hsp70 (27-29).

The Hsp90 inhibitor 17AAG is one of the most studied inhibitors of HSP90 (30-38). 17AAG destabilizes multiple tyrosine kinase receptors and other oncoproteins through Hsp90 inhibition, resulting in blocking of proliferation and induction of apoptosis.

In this study we tested the mechanism of action of rapamycin and 17AAG in osteosarcoma cell lines, HOS and KHOS/NP. HOS cells were derived from a female osteosarcoma patient and KHOS/NP cells were constructed by in vitro transfection of HOS cells with Kirsten murine sarcoma virus (Ki-MSV) (39). Unlike HOS cells, KHOS cells are capable of forming colonies in soft agar and form tumors in SCID mice.

We chose these cell lines for this osteosarcoma study because K-ras plays an important role in the biology of sarcoma and because these cell lines have been studied extensively before. The drugs used in this study, rapamycin and 17AAG are both promising target-specific drugs and could potentially be useful in the treatment of osteosarcoma patients.

We studied the effect of 17AAG and mTOR on apoptosis, mitochondrial membrane depolarization; the levels of reduced glutathione (GSH); and on proapoptotic and antiapoptotic proteins. We also determined the effects of these drugs on cell cycle; Akt/MAPK and the mTOR pathways. These targets, as well as other targets were studied because of parallel changes observed by gene microarray profiling (Gazitt, unpublished data). Our results indicate that 17-AAG is a good inducer of apoptosis in both osteosarcoma cell lines whereas rapamycin is less effective in inducing cell death and primarily affects cell growth. Preliminary results from this work have been presented (Gazitt et al, 100th Annual meeting of the American Association for Cancer Research, abs. 710, 2007).

\section{Materials and methods}

Cell lines and cell culture. HOS and KHOS/NP sarcoma cell lines were obtained from ATCC. Cultures were performed in Eagle's MEM medium containing $10 \%$ fetal calf serum (ATCC). HOS cells were derived from a female osteosarcoma patient and KHOS/NP cells were constructed by in vitro transfection of HOS cells with Kirsten murine sarcoma virus (39). Unlike HOS cells, KHOS cells are capable of forming colonies in soft agar and form tumors in SCID mice.

Determination of cell viability and apoptosis. Cell viability was determined by the trypan blue dye exclusion. Five hundred cells were counted in duplicate samples. To induce apoptosis cells were treated with 17-AAG or rapamycin (Sigma-Aldrich Inc., Dallas, TX) at concentrations of $0-10 \mu \mathrm{M}$ (rapamycin) or $0-1 \mu \mathrm{M}$ of 17AAG (Sigma-Aldrich) for 24 and $48 \mathrm{~h}$. For all assays adherent cells were detached by trypsin-EDTA and were combined with floating cells. Apoptosis was determined as before (40) by staining of exposed phosphatidylserine residues on apoptotic cells with Annexin V-FITC (BioVision, Palo Alto, CA). Stained cells were analyzed by flow cytometry (FACSAria, BDIS, San Jose, CA). Quantification of apoptosis was done by the Diva software. Twenty thousand cells were analyzed per sample.

Cell cycle analysis. The effect of 17AAG and rapamycin on cell cycle was determined by staining of cells with propidium iodide (PI) as previously described $(40,41)$. Adherent cells were detached by trypsin-EDTA and combined with floating cells. Stained cells were analyzed by flow cytometry (FACSAria; BDIS) and cell cycle analysis was performed using the ModFit software (BDIS). Twenty thousand cells were analyzed per sample.

Determination of mitochondrial membrane depolarization. Tetramethylrhodamine ethyl ester (TMRE; Molecular Probes, Eugene, OR) was used to detect mitochondrial membrane depolarization as previously described $(40,41)$. Briefly, cells $\left(2 \times 10^{5} / \mathrm{ml}\right)$ were cultured and rapamycin or $17-\mathrm{AAG}$ was added at various concentrations at the time-points indicated for each experiment. Adherent cells were detached by trypsin-EDTA and were combined with floating cells. For measurement of mitochondrial membrane depolarization, cells were harvested, washed and resuspended in FACSbuffer (PBS $+1 \%$ BSA) and TMRE (final concentration of $800 \mathrm{nM}$ ) was added and cells were further cultured for $20 \mathrm{~min}$ at $37^{\circ} \mathrm{C}$. Cells were then washed with FACS-buffer and the level of TMRE staining was determined by flow cytometry as previously described $(40,41)$. Quantification of the extent of mitochondrial membrane depolarization was performed by measurement of the left shift of TMRE fluorescence in cells with depolarized mitochondria. Samples were run in the FACSAria flow cytometer and results were analyzed by the FACSDiva software. Twenty thousand cells were analyzed per sample.

Determination of intracellular reduced glutathione. Monochlorobimane ( $\mathrm{mBCl}$; Molecular Probes) was used to detect reduced glutathione $(\mathrm{GSH}) . \mathrm{mBCl}$ is a thiol-reactive, mem- 
brane-permeable probe that fluoresces upon excitation at $405 \mathrm{~nm}$. Although $\mathrm{mBCl}$ reacts with all free thiol $(\mathrm{SH})$ groups, it preferentially forms adducts with the highly abundant cellular GSH in a reaction catalyzed by the enzyme glutathione- $S$-transferase (42). Assay was performed as described before (43). Briefly, cells $\left(5 \times 10^{5} / \mathrm{ml}\right)$ were cultured with various concentrations of rapamycin or $17-\mathrm{AAG}$ at the time-points indicated for each experiment. Adherent cells were detached by trypsin-EDTA and were combined with floating cells. For measurement of reduced GSH, cells were harvested, washed and resuspended in FACS-buffer (PBS + 1\% BSA). $\mathrm{mBCl}$ (dissolved in DMSO) was added at a final concentration of $200 \mu \mathrm{M}$ and cells were incubated at $37^{\circ} \mathrm{C}$ for $40 \mathrm{~min}$. Cells were then washed with FACS-buffer and $\mathrm{mBCl}$ fluorescence was determined by the FACSAria Flow Cytometer as above using the violet laser tuned to $407 \mathrm{~nm}$. Decrease in the level of reduced glutathione was measured by the extent of the left shift of $\mathrm{mBCl}$ fluorescence peak. Results were quantified by FACSDiva software. Twenty thousand cells were analyzed per sample.

Determination of apoptotic proteins, cells cycle proteins and cell signaling proteins by Western immunoblotting. Cells were cultured as described above with rapamycin or 17-AAG for the time-points indicated. Adherent cells were detached by trypsin-EDTA and were combined with floating cells. Aliquots of $5-10 \times 10^{6}$ cells were washed twice with PBS, total cellular protein was extracted and $50-100 \mu \mathrm{g}$ of protein was resolved by SDS-PAGE. Gel electrophoresis, immunoblotting and quantification of protein bands were performed by densitometry (Bio-Rad) as previously described $(43,44)$. Mouse monoclonal antibodies to Hsp70 (B6), Hsp90 (F8), Cdc2 (clone 17), cyclin D1 (A12), cyclin B1 (GNS1), GADD 45a (4-T27) were from Santa Cruz Biotechnology, Inc. (Santa Cruz, CA). Rabbit polyclonal anti-p-Cdc2, FLIP-s/l (G-11), GSK-3ß (0011A), p-GSK-3ß (ser9), PARP (250), TSC1/2, p-TSC1/2, and GADD 34 (S20) were also from Santa Cruz Biotechnology. Monoclonal antibodies to Akt1/2/3, p-Akt1/2/3 (ser 475), pro-caspase-9 (Asp 315), p44Erk; p-p44Erk, Akt, pAkt, mTOR, p-mTOR, p70S6, p-p70S6 were from Cell Signaling Technologies (Beverly, MA). Mouse monoclonal anti-active caspase-8 antibody was from NeoMarkers (Fremont, CA). Proteins were identified according to their migration on the blot using a ladder of biotinylated proteins (Bio-Rad). For loading controls, membranes were stripped and reprobed using mouse monoclonal anti- $\beta$-actin antibody (Clone AC-15; Sigma, St. Louis, MO).

Determination of cytosolic AIF, Hsp70 and Hsp90 by Western immunoblotting. Cells were cultured with rapamycin or 17-AAG for up to $48 \mathrm{~h}$. Adherent cells were detached by trypsin-EDTA and were combined with floating cells. Aliquots of $5-10 \times 10^{6}$ cells were washed twice with PBS and the cytosolic fraction was prepared by resuspending the cell pellets in mitochondria/cytosol buffer (BioVision) and passing the cell suspension 10 times through a 22 gauge syringe needle. Cell homogenate was centrifuged at $10,000 \mathrm{x} \mathrm{g}$ for $10 \mathrm{~min}$. at $4^{\circ} \mathrm{C}$ to obtain the cytosolic fraction $(40,43)$. For SDS-PAGE, $50 \mu \mathrm{g}$ of protein was loaded onto each lane. Gel electrophoresis, immunoblotting and quantification of protein bands were performed by densitometry as previously described (40). Mouse monoclonal antibody to AIF (Clone E-1) was from Santa Cruz Biotechnology. Cytosolic B-actin was used for loading control after stripping and reprobing as described above.

\section{Results}

Effect of 17AAG and rapamycin on apoptosis GSH, MMD and cell cycle in HOS and KHOS cells. We first tested 17-AAG and rapamycin for their potency to induce apoptosis as measured by Annexin V. HOS and KHOS cells were treated for 24 and $48 \mathrm{~h}$ with $0-1 \mu \mathrm{M}$ of $17-\mathrm{AAG}$ or $0-10 \mu \mathrm{M}$ of rapamycin. The results obtained after 24 and $48 \mathrm{~h}$ of treatment were similar. The results obtained after $48 \mathrm{~h}$ are depicted in Fig. 1A. The results indicated that $17-\mathrm{AAG}$ is a potent inducer of apoptosis in both sarcoma cell lines with an $\mathrm{IC}_{40}$ of $0.4 \mu \mathrm{M}$, at $48 \mathrm{~h}$. At this concentration of $17 \mathrm{AAG}$, the maximal mitochondrial membrane depolarization (MMD) was $40 \%$ and depletion of reduced glutathione (GSH) reached about 60\% (Fig. 1A). The effect of 17AAG on cell viability was also tested. As can be noted in Fig. 1A the decrease in cell viability followed closely the results obtained for apoptosis. Similar results were obtained for HOS and KHOS cells. Only the results for HOS cells are shown.

Rapamycin-induced apoptosis was also dose-dependent. However, rapamycin was a weaker inducer of apoptosis in both sarcoma cell lines $\left(\mathrm{IC}_{25}\right.$ of $4 \mu \mathrm{M}$, at $48 \mathrm{~h}$ ), involving a $40 \%$ decrease in reduced glutathione and $30 \%$ of cells exhibiting mitochondrial membrane depolarization (Fig. 1B). The effect of 17AAG on cell viability was also tested. As can be noted in Fig. 1B the decrease in cell viability followed closely the results obtained for apoptosis. Similar results were obtained for HOS and KHOS cells and only the results for HOS cells at $48 \mathrm{~h}$ are shown.

Rapamycin was shown to affect cell growth, whereas 17AAG was reported to exert mitotic block, in other cell types $(14,15)$. We therefore tested the effect of both drugs on cell cycle following $48 \mathrm{~h}$ of treatment. The results are depicted in Fig. 2. Treatment with 17AAG $(0-0.5 \mu \mathrm{M})$ caused a dose-dependent increase in the percentage of cells in $\mathrm{G} 2 / \mathrm{M}$ from 7.5 to $44.3 \%$ and from 6.2 to $52.7 \%$ for HOS and KHOS cells, respectively at maximal dose of 17AAG (Fig. 2). Arrows indicate $\mathrm{G} 2 / \mathrm{M}$ block. In contrast to $17 \mathrm{AAG}$, treatment with rapamycin at 0-5 $\mu \mathrm{M}$ (lower panel) resulted in blocking of cells in G1 (from 61.6 to $73 \%$ ) with a marked ( $90 \%$ ) decrease in S-phase at maximal dose of rapamycin used. Left arrows indicate G1 block and right arrows indicate the position of S-phase, No effect on G2/M was observed with rapamycin. Similar results for rapamycin were observed in KHOS cells (data not shown).

$17 A A G$ and rapamycin induced down-regulation of GSK3, $A k t / M A P K$ and $m T O R$. Previous studies have shown that $17 \mathrm{AAG}$ affects the Akt and MAP kinase pathway and rapamycin affects the mTOR pathway by a feedback loop mechanism (19). Our own studies of osteosarcoma cell lines using gene microarray profiling indicated changed in the expression of genes related to these pathways and the Wnt signaling pathway with a marked decrease in the expression 

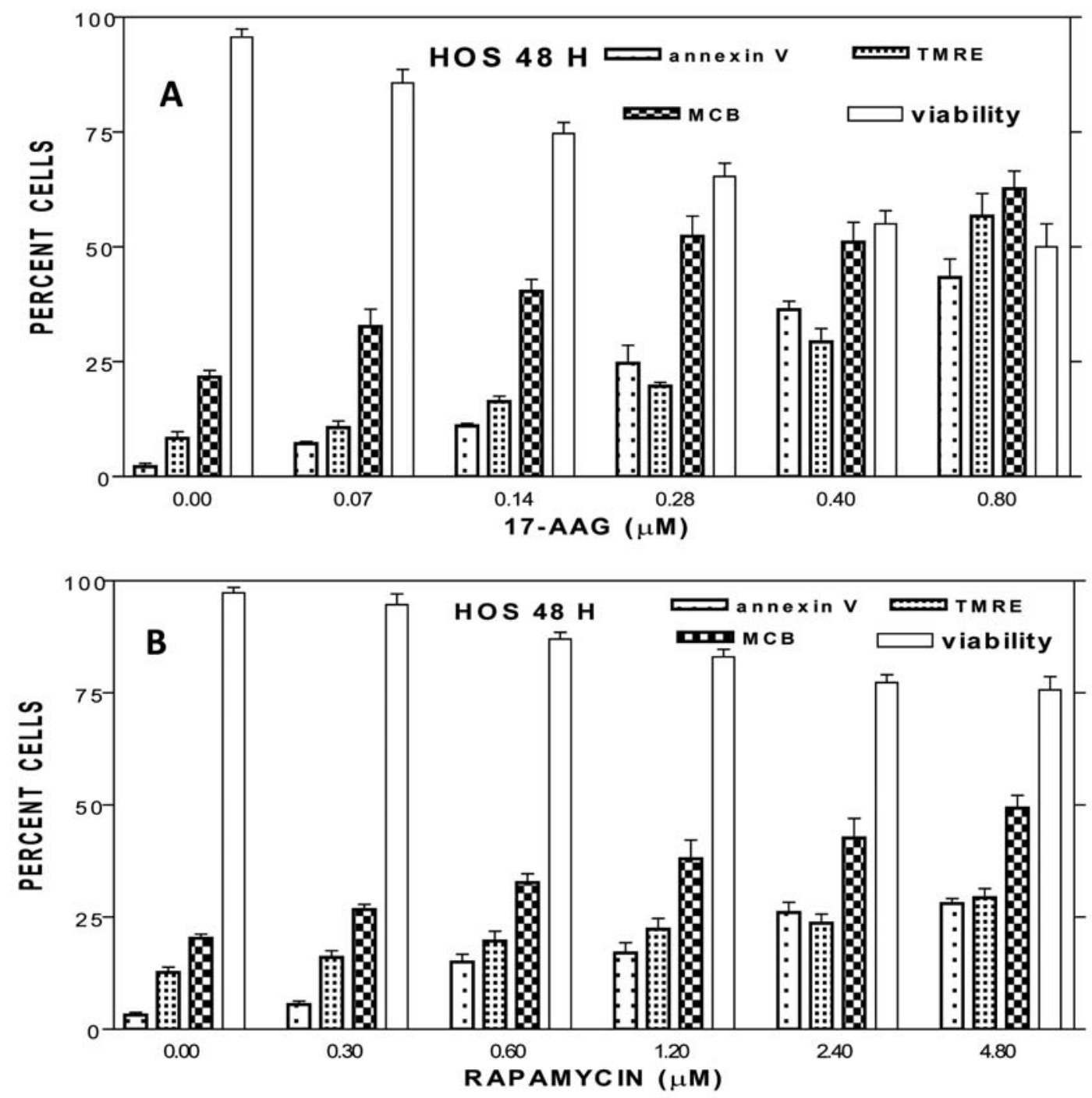

Figure 1. Effect of 17AAG and rapamycin on cell viability, apoptosis, GSH and MMD in HOS cells. Cells were treated for 24 and 48 h. Adherent cells were detached by trypsinization and were added to the floating cells. Apoptosis was determined by the extent of binding of Annexin V-FITC. Tetramethylrhodamine ethyl ester (TMRE) was used to detect mitochondrial membrane depolarization (MMD) and monochlorobimane (MCB) was used to detect the levels of reduced glutathione (GSH). Stained cells were analyzed by flow cytometry (FACSAria) and quantification was performed by the FACSDiva software. Bars represent the mean $\pm \mathrm{SD}$ from at least 3 different experiments. Cell viability was determined by the trypan blue dye exclusion. At least 500 cells were counted.

of GSK3ß (Gazitt, unpublished data). We therefore tested the effect of $17 \mathrm{AAG}$ or rapamycin on these cell signaling proteins in HOS and KHOS cells following 24 and $48 \mathrm{~h}$ of treatment. The results are depicted in Figs. 3 and 4. Following treatment with 17AAG (A) we observed substantial (50- 80\%) down-regulation of p-mTOR at 24 and $48 \mathrm{~h}$ in both cell lines, whereas rapamycin $(\mathrm{R})$ had little effect on mTOR and no effect on p-mTOR (Fig. 3). Only slight inhibition of the downstream protein, p70S6, was observed by either drug in HOS or KHOS cells with practically no effect on the level of p-p70S6 (Fig. 2). The glycogen synthase kinase-3ß (GSK-3ß) is the most important negative regulator of the $\mathrm{Wnt} / \mathrm{B}$-catenin pathway in mammalian cells $(45,46)$. Interestingly, both GSK-3ß and p-GSK-3 were markedly down-regulated (2-3-fold) by 17AAG in HOS and KHOS cells. No such effect was observed with rapamycin (Fig. 3).

We also tested the effect of 17AAG and rapamycin on upstream regulators of mTOR, TCS1/2 and pAkt and the p44
Erk of the MAPK pathway. The results are depicted in Fig. 4. Treatment with 17AAG (A) resulted in substantial downregulation of TSC1/2 (upper band, arrow) and complete disappearance of the phosphorylated form of p44 ERK and about $50 \%$ decrease in pAkt after $24-48 \mathrm{~h}$ of treatment in both cell lines. The levels of p44ERK or Akt were not affected by $17 \mathrm{AAG}$. In contrast to $17 \mathrm{AAG}$, rapamycin (R) had no effect on TSC1/2, p-p44ERK, or pAkt with mild inhibition observed for Akt at $48 \mathrm{~h}$. Similar effects were observed by each drug in both cell lines (Fig. 4).

Early effect of 17AAG and rapamycin on cell signaling and cell cycle regulatory proteins. To further investigate the kinetics of 17AAG and rapamycin-induced blocking of cell signaling and cell cycling, we examined early effects on the Akt, MAP/ERK kinase pathways, the mTOR signaling pathway and the cell cycle regulatory proteins, cyclin D1, cyclin B1, GADD45 and GADD34. HOS and KHOS cells 

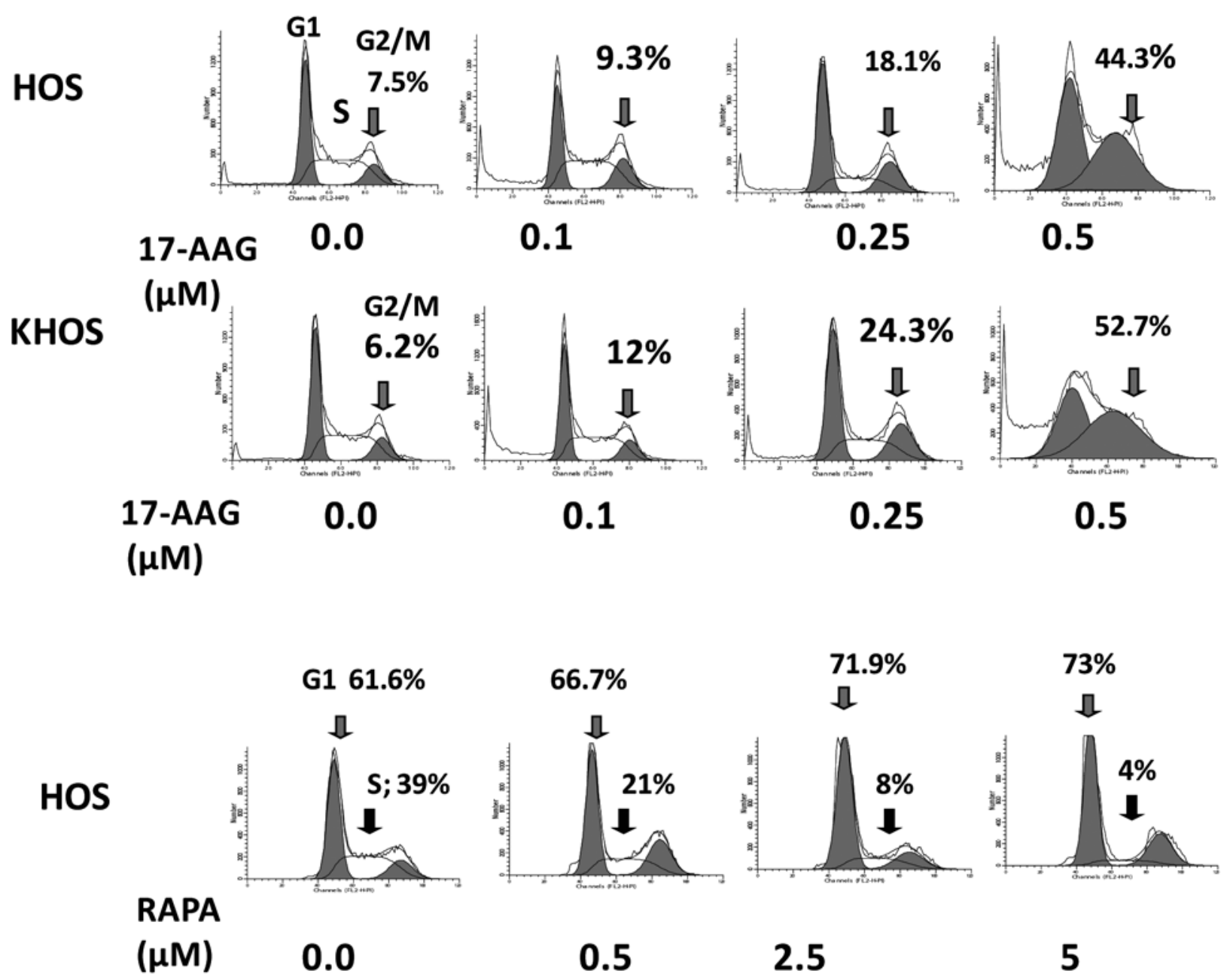

Figure 2. Effect of 17AAG and rapamycin on cell cycle in HOS and KHOS cells. Cells were treated for $48 \mathrm{~h}$. Adherent cells were detached by trypsinization and were added to the floating cells. Cell cycle was determined by staining of cells with propidium iodide and results were analyzed by flow cytometry (FACSCalibur) and quantified by the ModFit software. The position of G2/M is marked in cells treated with 17AAG. The position of G1 and S-phase are marked in cells treated with rapamycin. Left red peak represents cells in G1 whereas red right peak represents cells in G2/M. The hatched area between the 2 peaks represents cells in S-phase of the cell cycle. Treatment with 17AAG resulted in blocking of cells in mitosis, whereas, treatment with rapamycin resulted in blocking of cells in G1 and a marked decrease in S-phase. HOS and KHOS cells responded in a similar way to rapamycin (results for KHOS cells are not shown).

were cultured without serum for $4 \mathrm{~h}$ with or without rapamycin (4 $\mu \mathrm{M})$ or $17 \mathrm{AAG}(0.4 \mu \mathrm{M}$, T0). This was followed by adjusting the serum to $10 \%$ in order to stimulate growth signaling in these cultures. Serum-stimulated cultures with or without rapamycin $(4 \mu \mathrm{M})$ or 17AAG $(0.4 \mu \mathrm{M})$ were carried out. Cells were assayed at T0 (i.e. $4 \mathrm{~h}$ with no serum, with or without drugs) and at 1, 2, 4 and 24 h post-serum stimulation with or without drugs. Floating cells were combined with detached adherent cells. Cells were washed and total cellular protein was extracted and analyzed by Western immunoblotting for total Akt; p44Erk and TSC1/2 and their phosphorylated forms. The results for HOS cells are depicted in Fig. 5. A similar protocol was carried out for KHOS cells. Similar results were obtained for HOS and KHOS cells and only the results obtained with HOS cells are shown. As depicted in Fig. 5 treatment with $17 \mathrm{AAG}$ blocked phosphorylation of Akt, Erk and TSC1/2 at T0, before serum stimulation and at all other time-points tested. Interestingly, 17AAG down-regulated p-p44Erk, p-Akt, TSC1/2 and pTSC1/2, at all time-points tested. In contrast to 17AAG, rapamycin had no effect on Akt or Erk, TSC1/2, or their phosphorylated forms. A similar trend of results was observed for KHOS cells, although the effect was less robust (data not shown). These results suggest a very early effect of these drugs, before any measureable apoptotic event and further corroborate the results obtained for 24- and 48-h cultures depicted in Figs. 3 and 4. Furthermore, early down-regulation of p-p70S6, p-Akt and p-p44Erk were confirmed by flow cytometry with $>50 \%$ decrease in the number of positive cells and a 2-3-fold decrease in mean fluorescence intensity (MFI) observed for p-p70S6 p-p44Erk and p-Akt after 3-6 h of treatment with 17AAG (data not shown).

Similar cultures and stimulation conditions to those described above for cell signaling were employed to determine early effects on cell cycle regulatory proteins. The results are depicted in Fig. 6 for HOS cells. 17AAG and rapamycin slightly down-regulated (2- and 4-h points) GADD34 with no effect on GADD45a. Down-regulation of cyclin D1 was observed by 17AAG and rapamycin, before serum stimulation (T0) and at 1,2 and $24 \mathrm{~h}$ of serum stimulation. The levels of 


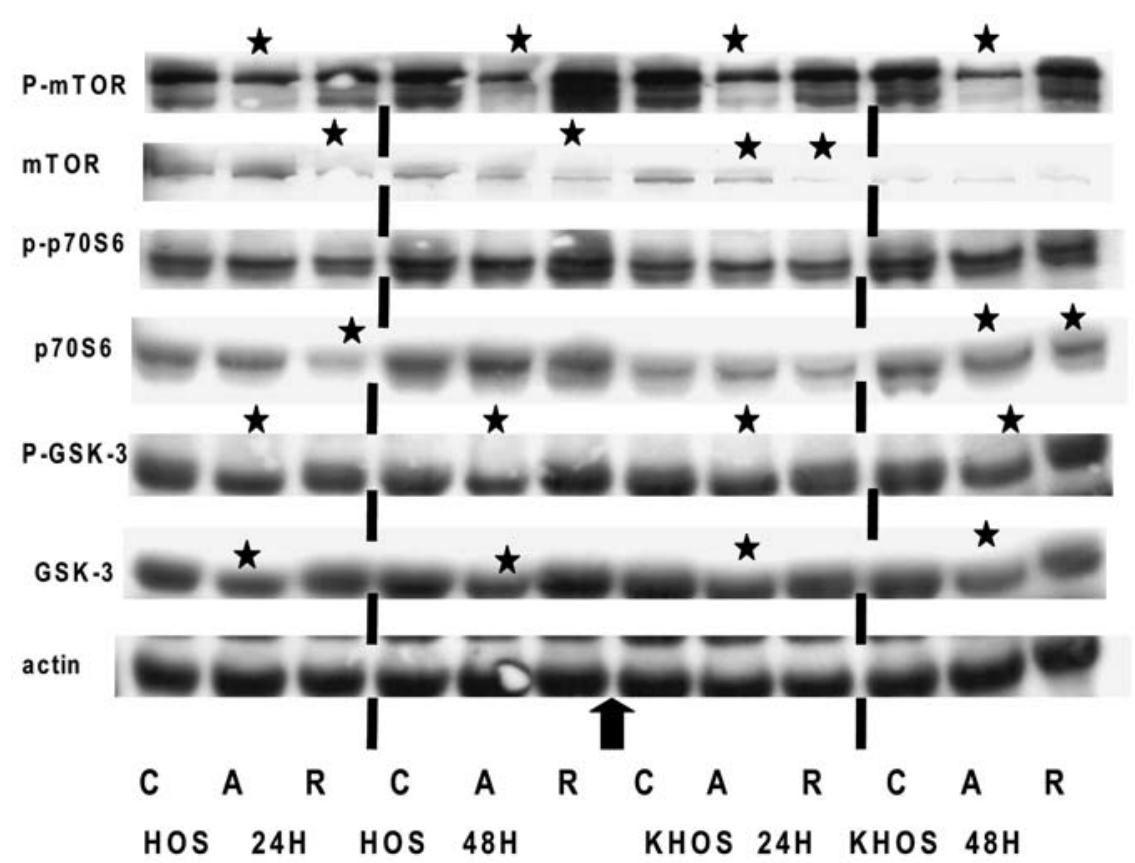

Figure 3. Effect of 17AAG and rapamycin on mTOR, p70S6 and GSK-3ß Cells were treated with $0.4 \mu \mathrm{M}$ of 17-AAG or $5 \mu \mathrm{M}$ of rapamycin. Adherent cells were detached by trypsinization and were added to the floating cells. Aliquots of 5-10x106 cells were washed with PBS and total cellular protein was extracted. 50-100 $\mu \mathrm{g}$ of protein was resolved by SDS-PAGE. Western immunoblotting was performed by standard procedures. Quantitation of protein band was done by densitometry. For loading controls, membranes were stripped and reprobed using mouse monoclonal anti- $\beta$-actin antibody. Vertical arrows distinguish HOS from KHOS. Lines distinguish $24 \mathrm{~h}$ from $48 \mathrm{~h}$ of treatment. Asterisks represent significant and reproducible changes. Results shown are representative of at least 3 experiments. C refers to control; A refers to 17AAG and R refers to rapamycin. Similar effects of 17AAG and rapamycin was noted for HOS and KHOS cells.

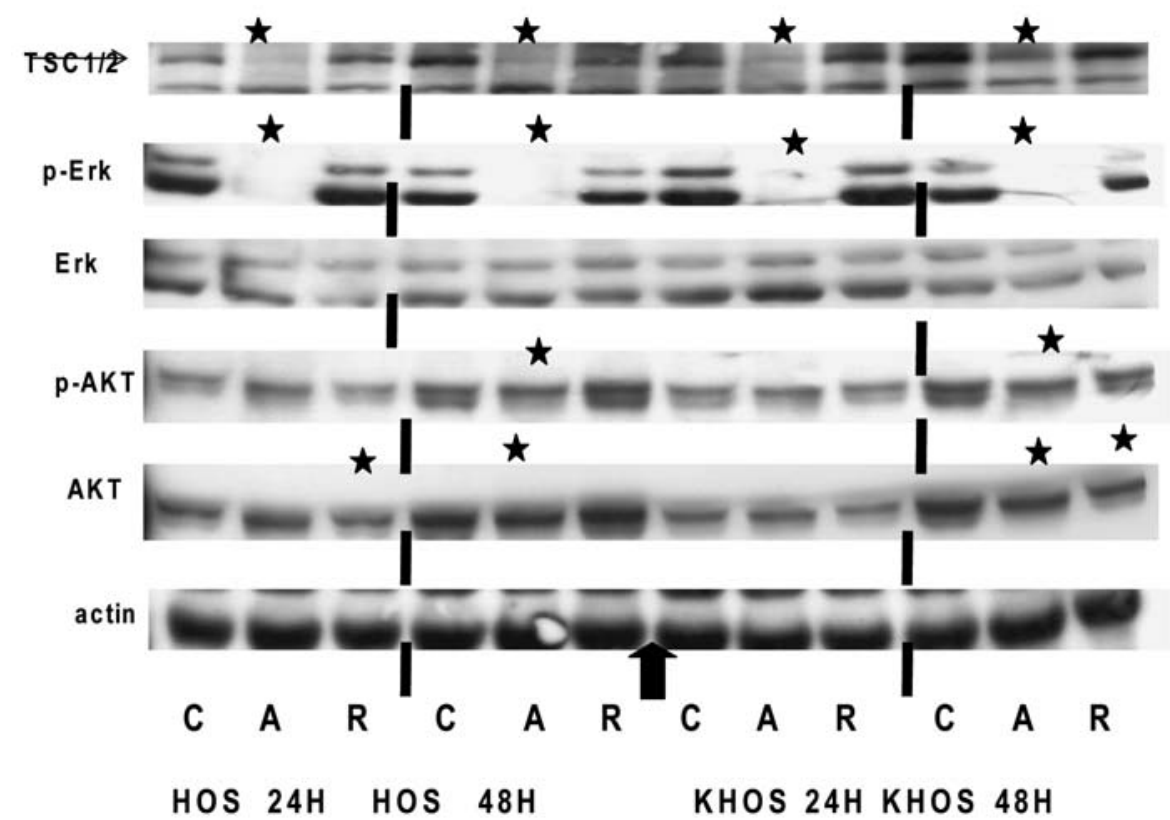

Figure 4. Effect of 17AAG and rapamycin on TSC1/2, Erk and Akt. Cells were treated with $0.4 \mu \mathrm{M}$ of 17-AAG or $5 \mu \mathrm{M}$ of rapamycin as described above. Adherent cells were detached by trypsinization and were added to the floating cells. Western immunoblotting was performed as described above (Fig. 3). Quantitation of protein band was done by densitometry. ß-actin was used for loading controls. Vertical arrows distinguish HOS from KHOS. Lines distinguish $24 \mathrm{~h}$ from $48 \mathrm{~h}$ of treatment. Asterisks represent significant and reproducible changes. Results shown are representative of at least 3 experiments. Horizontal arrow next to TSC1/2 band refers to the upper band of TSC1/2. C refers to control; A refers to 17AAG and R refers to rapamycin. Similar effects of 17AAG and rapamycin was noted for HOS and KHOS cells.

the mitotic cyclin, cyclin B1 were increased $24 \mathrm{~h}$ after stimulation by 17AAG (Fig. 6). Upregulation of cyclin B1 was confirmed also by flow cytometry with $>50 \%$ increase in percent positive cells observed as early as $9 \mathrm{~h}$ after treatment with 17AAG. Similar results were obtained for KHOS cells (data not shown). 


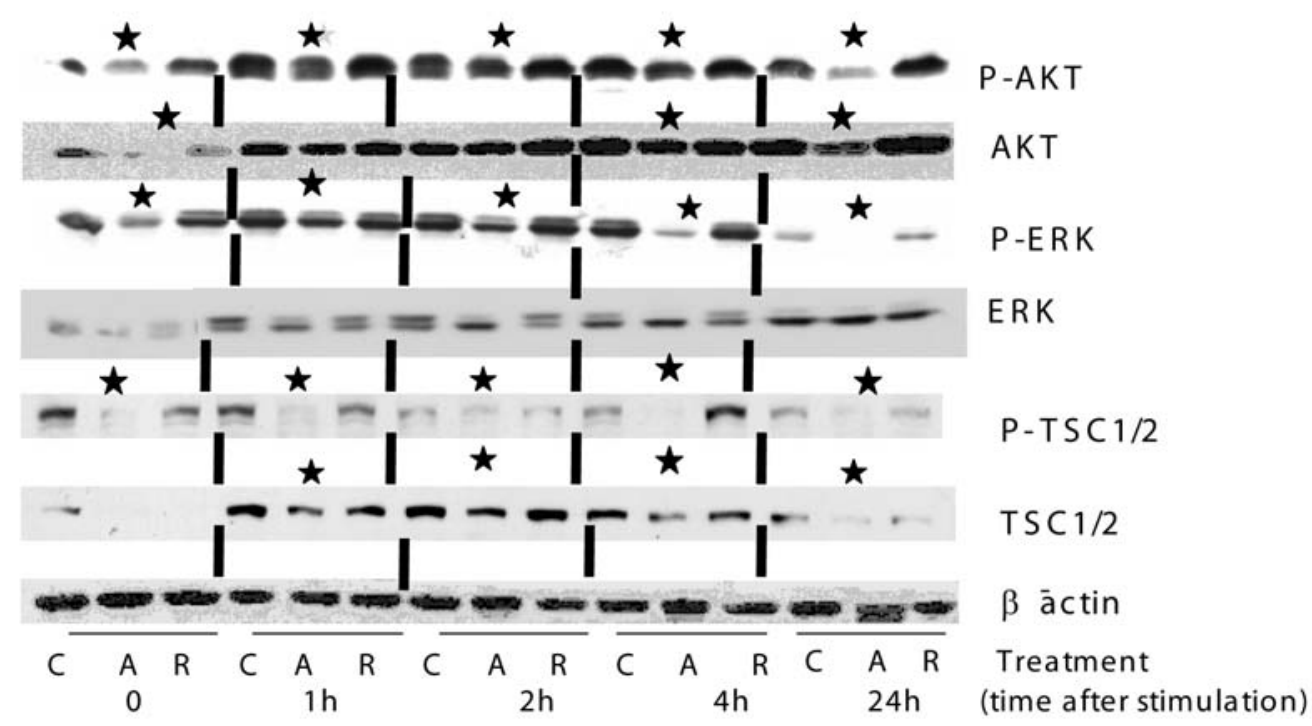

Figure 5. Early effects of 17AAG and rapamycin on cell signaling proteins in HOS cells. HOS cells were serum deprived for $4 \mathrm{~h}$ with or without $0.4 \mu \mathrm{M}$ of 17-AAG or $5 \mu \mathrm{M}$ of rapamycin and cell signaling was stimulated by addition of $10 \%$ serum with or without drugs for up to $24 \mathrm{~h}$. Adherent cells were detached by trypsinization and were added to the floating cells. Cultures were assayed before serum stimulation (T0) and 1,2, 4 and $24 \mathrm{~h}$ after stimulation as described in the text. Quantitation of protein band was done by densitometry. Lines distinguish different time-points of treatment. For loading controls, membranes were stripped and reprobed using mouse monoclonal anti- $\beta$-actin antibody. Asterisks represent significant and reproducible changes. Results shown are representative of at least 3 experiments. $\mathrm{C}$ refers to control; A refers to $17 \mathrm{AAG}$ and $\mathrm{R}$ refers to rapamycin.

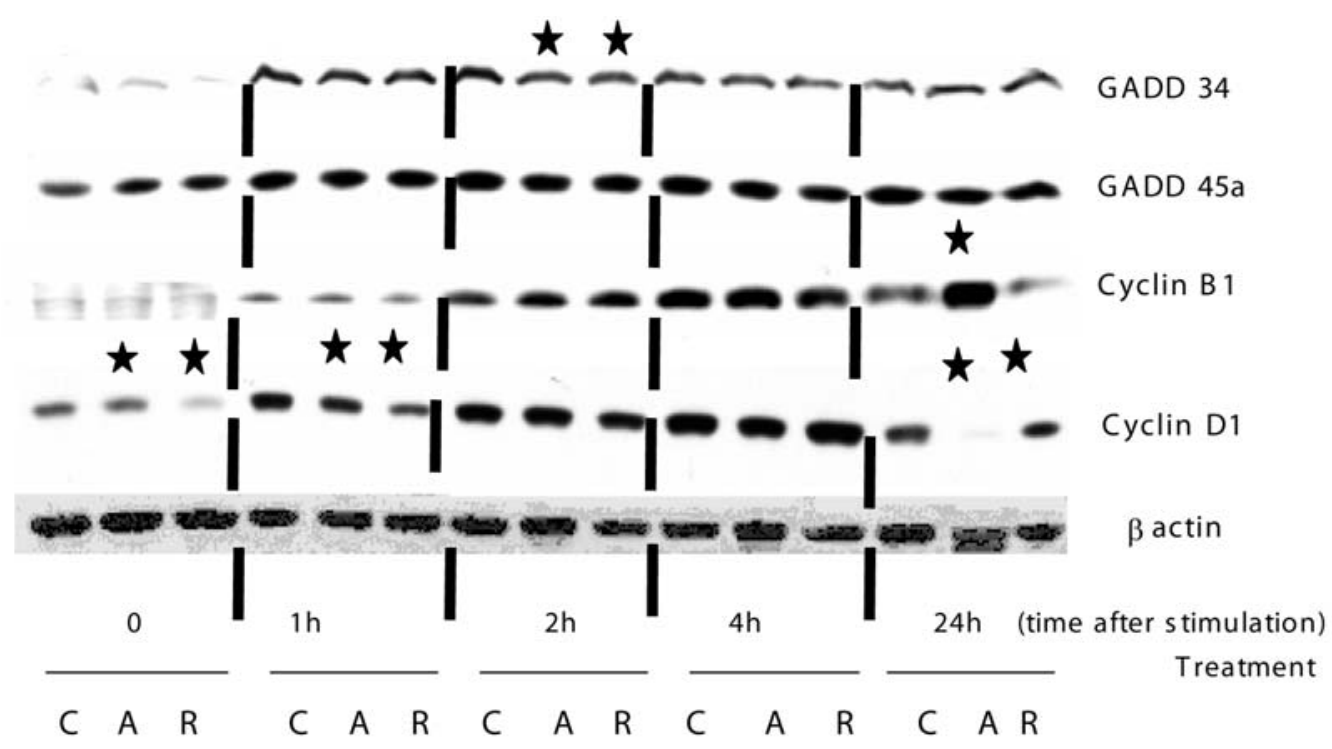

Figure 6. Early effects of 17AAG and rapamycin on cell cycle proteins in HOS cells. HOS cells were serum-deprived for $4 \mathrm{~h}$ with or without $0.4 \mu \mathrm{M}$ of 17 -AAG or $5 \mu \mathrm{M}$ of rapamycin and cell growth was stimulated by addition of $10 \%$ serum as described above in the legends to Fig 5. For loading controls, membranes were stripped and reprobed using mouse monoclonal anti- $\beta$-actin antibody. Quantitation of protein band was done by densitometry. Lines distinguish different time-points of treatment. Asterisks represent significant and reproducible changes. Results shown are representative of at least 3 experiments. C refers to control; A refers to $17 \mathrm{AAG}$ and $\mathrm{R}$ refers to rapamycin.

We then tested the long-term effect ( 24 and $48 \mathrm{~h}$ ) of $17 \mathrm{AAG}$ and rapamycin on cell cycle regulatory proteins. The results are depicted in Fig. 7. Cyclin D1 levels were decreased (40-60\%) by both drugs, whereas, cyclin B1 levels were increased (5-10-fold) by 17 AAG only (Fig. 7 compare to Fig. 6 above). In addition, we observed a decrease (2-5-fold) in the levels of the mitotic cyclin kinase Cdc2 and p-Cdc2 at 24 and $48 \mathrm{~h}$ of treatment with 17AAG. No such effect was observed with rapamycin. These changes in cyclins and Cdc2 were compatible with the cell cycle changes measured by propidium iodide staining and flow cytometry depicted in Fig. 2.

Effect of 17AAG and rapamycin on heat-shock proteins in HOS and KHOS cells. Previous studies revealed that treatment with 17AAG resulted in a small decrease (20-30\%) in Hsp90 and large increase (2-3-fold, $24 \mathrm{~h}, \mathrm{HOS}$ cells) in the level of Hsp70 and its C-terminal degradation fragments of $\sim 25 \mathrm{kDa}$ (26). We observed similar effect of 17AAG in osteosarcoma cells. The results are depicted in Fig. 8. Following 24 and 


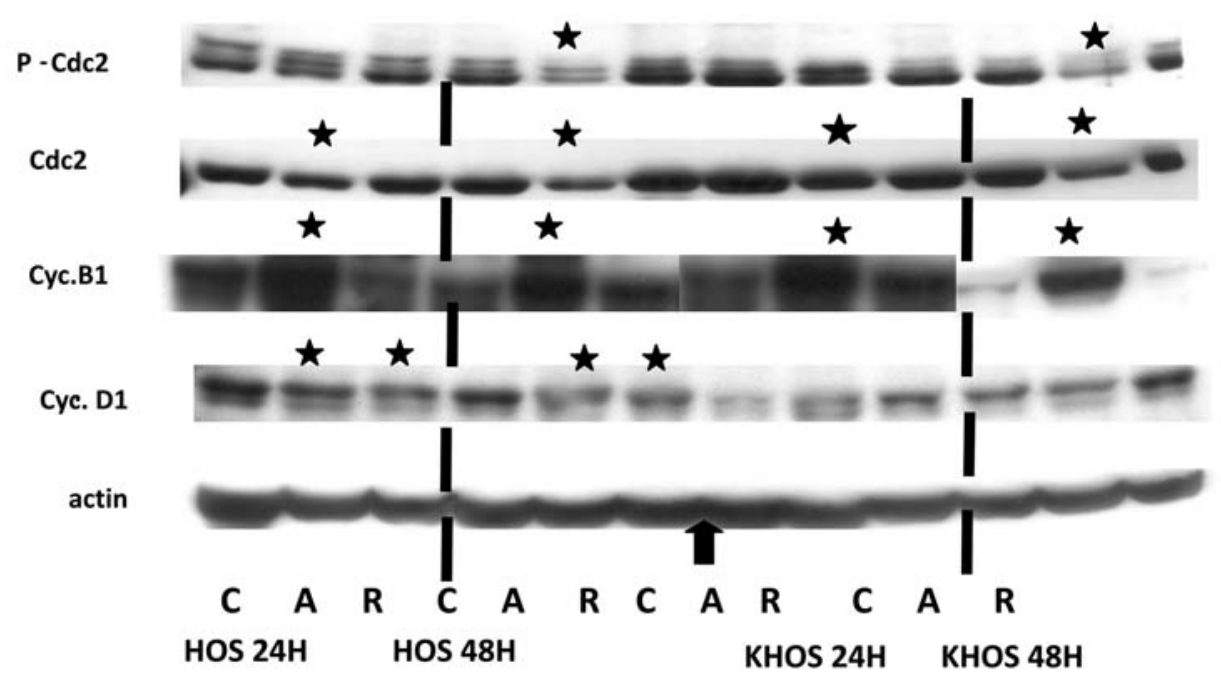

Figure 7. Effect of 17AAG and rapamycin on Cdc2, cyclin B1 and cyclin D1 in HOS and KHOS cells. Cells were cultured with $0.4 \mu \mathrm{M}$ of $17-\mathrm{AAG}$ or $5 \mu \mathrm{M}$ of rapamycin for 24 or $48 \mathrm{~h}$ as described in Materials and methods. Adherent cells were detached by trypsinization and were added to the floating cells. For loading controls, membranes were stripped and reprobed using mouse monoclonal anti- $\beta$-actin antibody. Quantitation of protein band was done by densitometry. Vertical arrows distinguish HOS from KHOS. Lines distinguish 24 from $48 \mathrm{~h}$ of treatment. Asterisks represent significant and reproducible changes. Results shown are representative of at least 3 experiments. C refers to control; A refers to 17AAG and R refers to rapamycin. Similar effects of 17AAG and rapamycin were noted for HOS and KHOS cells.

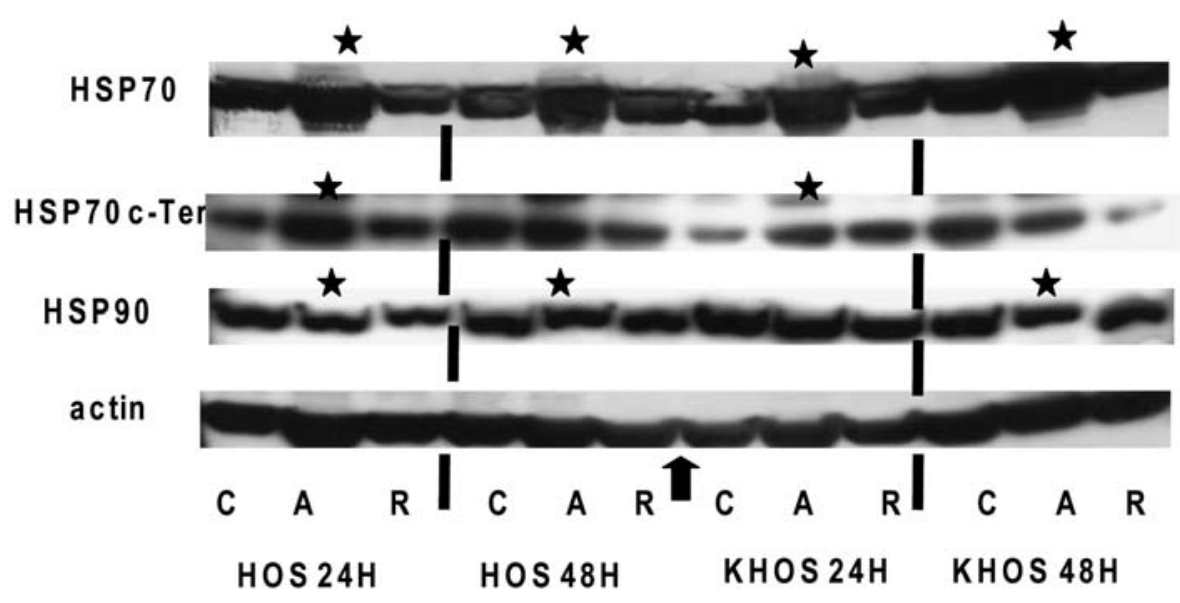

Figure 8. Effect of 17AAG and rapamycin on Hsp70 and Hsp90 in HOS and KHOS cells. Cells were cultured with $0.4 \mu \mathrm{M}$ of $17-\mathrm{AAG}$ or $5 \mu \mathrm{M}$ of rapamycin as described in the text. Other legends are as in Fig. 3. For loading controls, membranes were stripped and reprobed using mouse monoclonal anti- $\beta$-actin antibody. Quantitation of protein band was done by densitometry. Vertical arrows distinguish HOS from KHOS. Lines distinguish 24 from $48 \mathrm{~h}$ of treatment. Asterisks represent significant and reproducible changes. Results shown are representative of at least 3 experiments. C refers to control; A refers to 17AAG and $\mathrm{R}$ refers to rapamycin. An increase in cellular Hsp70 and its 30-kDa c-terminal fragment was noted in cells treated with 17AAG. Similar effects of 17AAG and rapamycin were noted for HOS and KHOS cells.

$48 \mathrm{~h}$ of treatment with $17 \mathrm{AAG}$ or rapamycin we observed a substantial increase in the levels of Hsp70 and an increase (24-h point) in the C-terminal fragment of Hsp70, concomitant with a small decrease in Hsp90 at the 48-h point. No such changes were observed with rapamycin. No major differences were observed between HOS and KHOS in this respect. These results were further confirmed by proteomics (Gazitt et al, unpublished data).

Effect of 17AAG and rapamycin on proapoptotic proteins in HOS and KHOS cells. In order to elucidate the apoptotic pathway of 17AAG and rapamycin in HOS and KHOS cells we measured the levels and activation of cellular and cytosolic apoptotic proteins. Fig. 9 depicts the effect of 17AAG and rapamycin on caspase-8, -9, FLIP and PARP. We also determined the cytosolic levels of the apoptosis inducing factor, AIF. The results indicate that treatment with $17 \mathrm{AAG}$ results in an increase in the activation of caspase- 9 as manifested by the decrease in the large peptide (upper band, horizontal arrow) of caspase-9. Treatment with $17 \mathrm{AAG}$ also resulted in a marked increase in the levels of activated caspase- 8 in HOS and KHOS cells (Fig. 9). Rapamycin had no effect on these caspases. Most importantly, the level of cytosolic AIF was markedly increased (3-5-fold) by $17 \mathrm{AAG}$, but not by rapamycin in both cell lines, at 24 and 48 h (Fig. 9). 


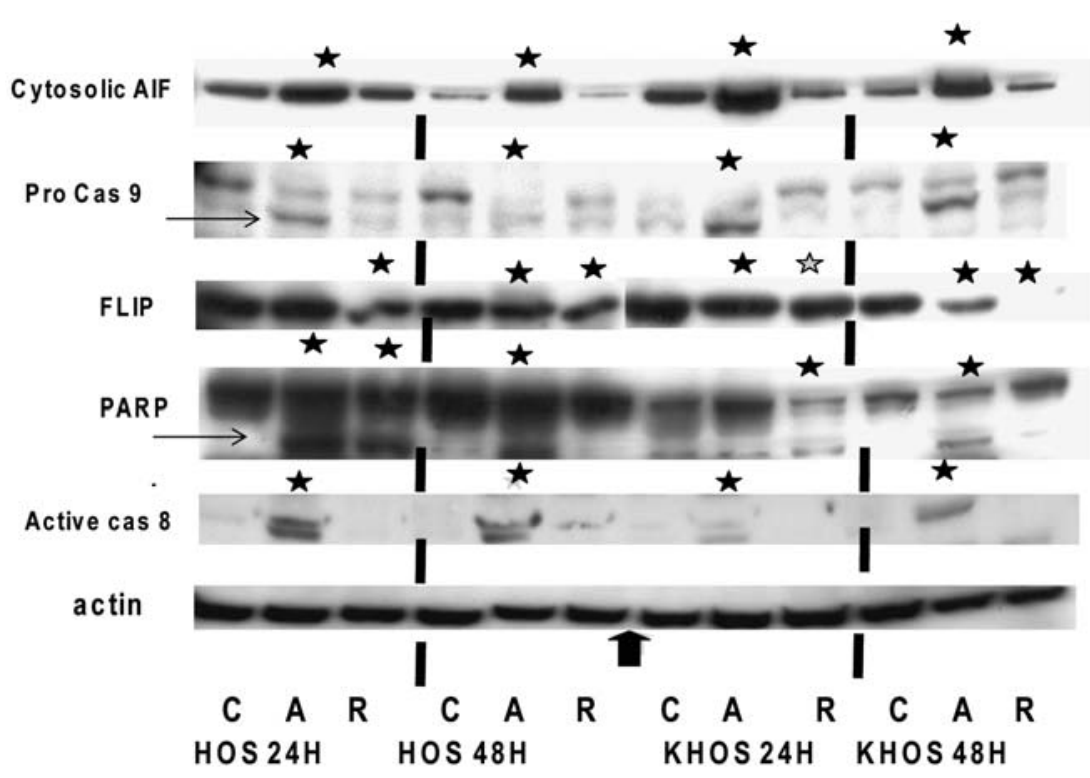

Figure 9. Effect of 17AAG and rapamycin on activation of caspases, PARP and FLIP/1 and on cytosolic AIF and Hsp70 in HOS and KHOS cells. Cells were cultured with $0.4 \mu \mathrm{M}$ of 17-AAG or $5 \mu \mathrm{M}$ of rapamycin as described in the text. Other legends are as in Fig. 3. Cytosolic fraction was isolated as described in Materials and methods. For loading controls, membranes were stripped and reprobed using mouse monoclonal anti- $\beta$-actin antibody. Quantitation of protein band was done by densitometry. Vertical arrows distinguish HOS from KHOS. Lines distinguish 24 from 48 h of treatment. Horizontal arrows indicate degradation peptides in caspase-9 and PARP lanes. Asterisks represent significant and reproducible changes. Results shown are representative of at least 3 experiments. $\mathrm{C}$ refers to control; A refers to $17 \mathrm{AAG}$ and $\mathrm{R}$ refers to rapamycin. An increase in cytosolic AIF and Hsp70 was noted in cells treated with 17AAG. Similar effects of 17AAG and rapamycin were noted for HOS and KHOS cells.

FLIP was decreased (5-10-fold) by both drugs at 24 and $48 \mathrm{~h}$, especially in KHOS cells. Similarly, PARP was activated by both drugs with appearance of the $94-\mathrm{kDa}$ degradation product (e.g., HOS $24 \mathrm{~h}$; horizontal arrow).

These results, taken together, suggest that 17AAG activates the intrinsic and the extrinsic apoptotic pathways involving activation of caspase- 8 and -9 and AIF in HOS and KHOS cells. In addition, 17AAG strongly deactivated the MAP/ ERK/AKT/B-catenin and mTOR pathways and blocked cells in mitosis concomitant with upregulation of the mitotic cyclin, cyclin B1 and down-regulation of the mitotic cyclin kinase, Cdc2. The effect of rapamycin, on the other hand, was predominantly on cell growth (G1 arrest) and depletion of S-phase, through blocking of mainly the mTOR pathway. These results explain the weaker apoptotic effect of rapamycin observed in these cell lines.

\section{Discussion}

Targeted therapy has become the mainstay of novel chemotherapy across all types of cancer. The most popular experimental and therapeutic targets involve angiogenesis; cancer survival pathways, such as the Akt/MAPK and mTOR pathways; apoptosis; and cell-cycle checkpoints. Many of these drugs are in various stages of preclinical and clinical development. However, scant information is known on the activity of this type of drugs in osteosarcoma, known for its drug-resistance. Hence, we undertook the task of detailed analysis of the mode of action of 2 promising target-specific drugs, 17AAG and rapamycin. Our results confirm results obtained previously by others for other solid tumors and report novel effects on targets not reported before for these drugs.
Mechanism of action of 17 AAG in osteosarcoma cells. Our results indicate that 17-AAG is a potent inducer of apoptosis in both sarcoma cell lines, involving early depletion of GSH, mitochondrial membrane depolarization and strong activation of caspase- 8 and caspases- 9 and activation of PARP. Among the new effects we observed down-regulation of FLIP and translocation of AIF from mitochondria to the cytosol. These combined observations suggest activation of multiple targets in the intrinsic and extrinsic apoptotic pathways as a result of blocking of Hsp90 as previously described for other cell types (23).

The most impressive effect of 17AAG was the very early and strong inhibition of the phosphorylated forms of p44Erk, GSK-3ß, Akt, mTOR and TSC1/2. Blocking of p44Erk and Akt by 17AAG has been reported before for other cell types (25). However, down-regulation of GSK-3ß pGSK-3ß by 17AAG have not been reported before. The reported effect of $17 \mathrm{AAG}$ on GSK-3ß and pGSK-3ß are important since $\beta$-catenin and GSK-3ß play an important role in the etiology of osteosarcoma. Furthermore, GSK-3ß is an important client protein of Hsp90 and the Hsp90 chaperone activity is needed to stabilize the authophosphorylation and constitutive activation of pGSK-3ß (48). Thus, blocking of Hsp90 by 17AAG may have resulted in stabilization of $\beta$-catenin and its many signaling pathways including cell cycle (e.g., cyclin D1, differentiation and apoptosis) $(48,49)$. Down-regulation of GSK-3ß and cyclin D1 has been reported following knockdown (by SiRNA) of Cdc37, a co-chaperone of Hsp90 (49). We therefore suggest that at least part of the cell cycle and apoptotic effect observed with 17AAG resulted from blocking of GSK-3ß.

We also observed a profound effect of 17AAG on the cell cycle with a strong anti-mitotic activity, concurrent 
with upregulation of the mitotic cyclin, cyclin B1 and downregulation of the mitotic cyclin-dependent kinase, $\mathrm{Cdc} 2$ and its phosphorylated form. The observed mitotic block by 17AAG was confirmed by confocal imaging (Gazitt, unpublished data) and has been reported before for other cell types $(25,49)$. 17AAG also down-regulated the G1 cyclin, cyclin D1, the DNA damage-related transcription factor GADD34 (50,51), but had no effect on the G1/S transcription factor, GADD45a (52). The observed decrease in cyclin D1 and GADD34 was confirmed independently in our lab using gene microarray analyses (Gazitt et al, 43rd Annual meeting of ASCO, abs. 10027, 2007). Based on these data and the low activity of the small responses obtained in phase I clinical trials in patients with solid tumors (53) we suggest that $17 \mathrm{AAG}$ could be used as a single drug for the treatment of osteosarcoma, but could be more effective if combined with other targeting drugs. In this respect, we are currently testing the combination of histone deacetylase inhibitors and 17AAG and preliminary results suggest synergy with 17AAG (Gazitt et al, unpublished data).

In addition, treatment with $17-\mathrm{AAG}$ resulted in a marked increase in the levels of Hsp70 and Hsp70 degradation peptide known as the $\mathrm{C}$-terminal fragment $(\sim 25 \mathrm{kDa})$. This finding is in agreement with the previously reported effect of blocking Hsp90 in other cell types $(23,26)$. Hsp70 confers multiple antiapoptotic activities including blocking of the activation of caspase- 9 and -3 and blocking of AIF and cytochrome $\mathrm{c}$ release to the cytosol and the ensuing apoptosis $(26,47)$. Hence, the observed enhanced turnover of Hsp70 could have contributed to induced apoptosis. The observed increase in Hsp70 and its C-terminal fragment were confirmed independently by gene microarray profiling and proteomics using 2-D gels, mass spectrometry and direct sequencing (Gazitt et al, 100th Annual meeting of the American Association for Cancer Research, abs. 3702, 2007).

Mechanism of action of rapamycin in osteosarcoma cells. In our hands, the major effect of rapamycin in osteosarcoma cells was growth inhibition as manifested by down-regulation of cyclin D1, G1 arrest and in a marked decrease in the percent of cells in S-phase of the cell cycle. These effects of rapamycin have been described before for other cell types $(14,15)$. On the other hand, rapamycin was less potent in the induction of apoptosis and treatment resulted in only a small decrease in GSH and mitochondrial damage, with no activation of caspases-8, -9, AIF, or in activation of PARP. Most importantly, rapamycin down-regulated Akt and mTOR but had no effect on p-mTOR, TSC1/2, GSK-3ß and p44Erk. A small inhibitory effect was observed for Akt and mTOR. It is noteworthy that in preliminary studies we observed no synergy or additivity between $17 \mathrm{AAG}$ and rapamycin when the 2 drugs were combined. In fact we observed a slight antagonistic effect. This could be the result of early blocking of cells in G1 which could result in a decrease in the potency of 17AAG which induces a mitotic block. Alternatively, lack of additivity or synergy could be the result of the previously documented activation of Akt as a result of blocking of mTOR.

Finally, it is noteworthy that osteosarcoma cell lines used in this study, HOS and KHOS were equally sensitive to both drugs despite the fact that KHOS cells are capable of forming colonies in soft agar and tumors in SCID mice (39).

\section{Acknowledgements}

This work was supported by a generous pilot study grant (Y.G.) from the Cancer Research and Therapy Center at UT Health Science Center, San Antonio. The Flow Cytometry work was performed at the Institutional/CTRC Flow Cytometry Core Facility at UT Health Science Center.

\section{References}

1. Brecht IB and Treuner J: Soft tissue sarcoma in children and adolescents: experiences of the cooperative Soft Tissue Sarcoma Group Studies (CWS-81-96). Handchir Mikrochir Plast Chir 36: 275-281, 2004.

2. Jemal A, Murray T, Ward E, et al: Cancer statistics 2005. CA Cancer J Clin 55: 10-30, 2005.

3. O'Bryan RM, Baker LH, Gottlieb JE, et al: Dose response evaluation of adriamycin in human neoplasia. Cancer 39: 1940-1948, 1977.

4. Antman KH, Ryan L, Elias A, et al: Response to ifosfamide and mesna: 124 previously treated patients with metastatic or unresectable sarcoma. J Clin Oncol 7: 126-131, 1989.

5. Antman K, Crowley J, Balcerzak SP, et al: An intergroup phase III randomized study of doxorubicin and dacarbazine with or without ifosfamide and mesna in advanced soft tissue and bone sarcomas. J Clin Oncol 11: 1276-1285, 1993.

6. Patel SR, Vadhan-Raj S, Burgess MA, et al: Results of two consecutive trials of dose-intensive chemotherapy with doxorubicin and ifosfamide in patients with sarcomas. Am J Clin Oncol 21: 317-321, 1998.

7. Edmonson JH, Ryan LM, Blum RH, et al: Randomized comparison of doxorubicin alone versus ifosfamide plus doxorubicin or mitomycin, doxorubicin, and cisplatin against advanced soft tissue sarcomas. J Clin Oncol 11: 1269-1275, 1993.

8. Verweij J, Lee SM, Ruka W, et al: Randomized phase II study of docetaxel versus doxorubicin in first- and second-line chemotherapy for locally advanced or metastatic soft tissue sarcomas in adults: a study of the European organization for research and treatment of cancer soft tissue and bone sarcoma group. J Clin Oncol 18: 2081-2086, 2000.

9. Kasper B, Gil T and Awada A: Treatment of patients with advanced soft tissue sarcoma: disappointment or challenge? Curr Opin Oncol 19: 336-340, 2007.

10. Fahn W and Issels RD: Emerging treatments for soft tissue sarcoma of adults. Exp Opin Emerg Drugs 9: 313-343, 2004.

11. Tsai YC, Wu CT and Hong RL: Response of refractory osteosarcoma to thalidomide and celecoxib. Lancet Oncol 6: 997-999, 2005.

12. Balasubramanian L and Evens AM: Targeting angiogenesis for the treatment of sarcoma. Curr Opin Oncol 18: 354-359, 2006.

13. Okuno S: Mammalian target of rapamycin inhibitors in sarcomas. Curr Opin Oncol 18: 360-362, 2006.

14. Martin DE and Hall MN: The expanding TOR signaling network. Curr Opin Cell Biol 17: 158-166, 2005

15. Sarbassov dos D, Ali SM and Sabatini DM: Growing roles for the mTOR pathway. Curr Opin Cell Biol 17: 596-603, 2005

16. Vignot S, Faivre S, Aguirre D and Raymond E: mTOR-targeted therapy of cancer with rapamycin derivatives. Ann Oncol 16: 525-537, 2005.

17. Inoki K, Corradetti MN and Guan KL: Dysregulation of the TSC-mTOR pathway in human disease. Nat Genet 37: 19-24, 2005.

18. Petroulakis E, Mamane Y, Le Bacquer O, et al: mTOR signaling: implications for cancer and anticancer therapy. Br J Cancer 94: 195-199, 2006,

19. Morgensztern D and McLeod HL: PI3K/Akt/mTOR pathway as a target for cancer therapy. Anticancer Drugs 16: 797-803, 2005.

20. Cohen E: mTOR inhibitors. Clin Adv Hematol Oncol 4: 38-39, 2006.

21. Mita MM, Mita AC, Chu QS, et al: Phase I trial of the novel mammalian target of rapamycin inhibitor deforolimus (AP23573; MK-8669) administered intravenously daily for 5 days every 2 weeks to patients with advanced malignancies. J Clin Oncol 26: 361-367, 2008. 
22. Hidalgo M, Buckner JC, Erlichman C, et al: A phase I and pharmacokinetic study of temsirolimus (CCI-779) administered intravenously daily for 5 days every 2 weeks to patients with advanced cancer. Clin Cancer Res 12: 5755-5763, 2006.

23. Sreedhar AS and Csermely P: Heat-shock proteins in the regulation of apoptosis: new strategies in tumor therapy: a comprehensive review. Pharmacol Ther 101: 227-257, 2004

24. Isaacs JS, Xu W and Neckers L: Heat-shock protein 90 as a molecular target for cancer therapeutics. Cancer Cell 3: 213-217, 2003.

25. Hostein I. Robertson D, Di Stefano F, et al: Inhibition of signal transduction by the Hsp90 inhibitor 17-allylamino-17demethoxygeldanamycin results in cytostasis and apoptosis. Cancer Res 61: 4003-4009, 2001

26. Mosser DC and Morimoto IR: Molecular chaperones and the stress of oncogenesis. Oncogene 23: 2907-2918, 2004.

27. Zylicz M, King FW and Wawrzynow A: Hsp70 interactions with the p53 tumour suppressor protein. EMBO J 20: 4634-4638, 2001.

28. Walerych, D, Kudla, G, Gutkowska M, et al: Hsp90 chaperones wild-type p53 tumor suppressor protein. J Biol Chem 279: 48836-48845, 2004

29. Müller P, Ceskova P and Vojtesek B: Hsp90 is essential for restoring cellular functions of temperature- sensitive p53 mutant protein but not for stabilization and activation of wild-type p53: implications for cancer therapy. J Biol Chem 280: 6682-6691, 2004.

30. Zhang $\mathrm{H}$ and Burrows F: Targeting multiple signal transduction pathways through inhibition of Hsp90. J Mol Med 82: 488-499, 2004.

31. Workman P: Overview: Translating Hsp90 biology into Hsp90 drugs. Curr Cancer Drug Targets 3: 297-300, 2003.

32. Xiao L, Lu X and Ruden DM: Effectiveness of hsp90 inhibitors as anti-cancer drugs. Mini Rev Med Chem 6: 1137-1143, 2006.

33. Drysdale MJ, Brough PA, Massey A, et al: Targeting Hsp90 for the treatment of cancer. Curr Opin Drug Discov Devel 9: 483-495, 2006.

34. Park JW, Yeh MW, Wong MG, et al: The heat-shock protein 90-binding geldanamycin inhibits cancer cell proliferation, down-regulates oncoproteins, and inhibits epidermal growth factor-induced invasion in thyroid cancer cell lines. J Clin Endocrinol Metab 88: 3346-3353, 2003.

35. Solit DB, Zheng FF, Drobnjak M, et al: 17-Allylamino-17demethoxygeldanamycin induces the degradation of androgen receptor and HER-2/neu and inhibits the growth of prostate cancer xenografts. Clin Cancer Res 8: 986-993, 2002.

36. An WG, Schulte TW and Neckers LM: The heat-shock protein 90 antagonist geldanamycin alters chaperone association with p210bcr-abl and v-src proteins before their degradation by the proteasome. Cell Growth Differ 11: 355-360, 2000.

37. Dymock BW, Barril X, Brough PA, et al: Novel, potent smallmolecule inhibitors of the molecular chaperone Hsp90 discovered through structure-based design. J Med Chem 48: 4212-4215, 2005 .
38. Terry J, Lubieniecka JM, Kwan W, et al: Hsp90 inhibitor 17allylamino-17-demethoxygeldanamycin prevents synovial sarcoma proliferation via apoptosis in vitro models. Clin Cancer Res 11: 5631-5638, 2005.

39. Ikeda T, Futaesaku Y and Tsuchida $\mathrm{N}$ : In vitro differentiation of the human osteosarcoma cell lines, HOS and KHOS. Virchows Arch B Cell Pathol 62: 199-206, 1992.

40. Liu Q, Hilsenbeck S and Gazitt Y: Arsenic trioxide-induced apoptosis in myeloma cells: p53 dependent G1 or G2/M cell cycle arrest, activation of caspase- 8 or caspase- 9 and synergy with APO2/Trail. Blood 101: 4078-4087, 2003.

41. Akay C, Thomas C and Gazitt Y: Arsenic trioxide and paclitaxel induce apoptosis by different mechanisms. Cell Cycle 3: 324-334, 2004.

42. Hedley DW and Chow S: Evaluation of methods for measuring cellular glutathione content using flow cytometry. Cytometry 15: 349-358, 1994.

43. Akay $\mathrm{C}$ and Gazitt $\mathrm{Y}$ : Arsenic trioxide selectively induces early and extensive apoptosis via the APO2/caspase-8 pathway engaging the mitochondrial pathway in myeloma cells with mutant p53. Cell Cycle 2: 358-368, 2003.

44. Liu Q and Gazitt Y: Potentiation of dexamethasone,taxol and Ad-p53-induced apoptosis by bcl-2 anti-sense oligodeoxynucleotides in drug-resistant multiple myeloma cells. Blood 101: 4105-4114, 2003.

45. Moon TR, Bowerman B, Boutros M, et al: The promise and perils of Wnt signaling through $B$-catenin. Science 296: 1644-1647, 2002.

46. Doble BW and Woodgett JR: GSK-3: tricks of the trade for a multi-tasking kinase. J Cell Sci 116: 1175-1186, 2003

47. Schmitt E, Gehrmann M, Brunet M, et al: Intracellular and extracellular functions of heat-shock proteins: repercussions in cancer therapy. J Leukoc Biol 81: 15-27, 2007.

48. Lochhead PA, Kinstrie R, Sibbet G, et al: A chaperone-dependent GSK3beta transitional intermediate mediates activation-loop authophosphorylation. Mol Cell 24: 627-633, 2006.

49. Gray PJ Jr, Stevenson MA and Calderwood SK: Targeting Cdc37 inhibits multiple signaling pathways and induces growth arrest in prostate cancer cells. Cancer Res 67: 11942-11950, 2007.

50. Hung WJ, Roberson RS, Taft J, et al: Human BAG-1 proteins bind to the cellular stress response protein GADD34 and interfere with GADD34 functions. Mol Cell Biol 23: 3477-3486, 2003

51. Hollander MC, Zhan Q, Bae I and Fornace AJ Jr: Mammalian GADD34, an apoptosis- and DNA damage-inducible gene. J Biol Chem 272: 13731-13737, 1997.

52. DeWolf WC and Gaston SM: The cell cycle and its relevance to the urologist. J Urol 171: 1674-1681, 2004.

53. Ramanathan RK, Trump DL, Eiseman JL, et al: Phase I pharmacokinetic-pharmacodynamic study of 17-(allylamino)17-demethoxygeldanamycin (17AAG, NSC 330507), a novel inhibitor of heat-shock protein 90 , in patients with refractory advanced cancers. Clin Cancer Res 11: 3385-3391, 2005. 